\title{
TRATAMIENTO DE LA TRICONOMIASIS GENITAL CON UN NUEVO QUIMIOTERAPICO: LA NITROIMIDAZINA
}

\author{
Dr. Alvaro Fonngera Miramón* \\ Dr. Arturo Rodríguez Soto** \\ Dr. Hernando Quiñones Borda***
}

\section{Enfoque general del problema de la Tricomoniasis Genital}

No obstante que el germen conocido como trichomonas vaginalis fue descrito por Bonné en 1836, su importancia como agente etiológico de la tricomoniasis no se apreció hasta hace pocos años.

Actualmente la tricomoniasis genital se cataloga como una afección conyugal y por lo tanto debe ser considerada desde el punto de vista epidemiológico como una enfermedad venérea, ya que los focos de la infección se localizan de preferencia en la vagina, glándulas vestibulares, cuello uterino y en la uretra del hombre y de la mujer. Además, pueden existir focos en la próstata y vesículos seminales del hombre (6).

Por estas razones su tratamiento debe ser no sólo local para la mujer, sino sistémico para los cónyuges. Este tratamiento simultáneo es básico para evitar el peligro de la reinfección.

La infección es extraordinariamente frecuente en todo el mundo (5); en Colombia presenta en los últimos tiempos cifras muy altas de incidencia, pues a pesar de que se trata con múltiples drogas, la asociación del parásito con gérmenes inespecíficos y la presencia de múltiples focos a los cuales no llega la droga, hacen difícil su tratamiento.

Para la terapia racional de la tricomoniasis es necesario, utilizar un fármaco de segura eficacia y de máxima tolerancia, tanto por la vía oral, como tópicamente.

Por estas razones hemos experimentado un nuevo tricomoniacida sistémico y tópico, sintetizado y estudiado por el "Instituto de Investigaciones Carlo Erba", definido con el nombre químico genérico de -"Nitro imidazina" (*).

El interés en los compuestos nitroimidazólicos como tricomonicidas sintéticos, se inició en 1956 cuando Horie y Despois demostraron la actividad del Azomicin (1).

* Profesor Asociado del Departamento de Ginecología y Obstetricia de la Facultad de Medicina, de la Universidad Nacional.

** Instructor Asociado del Departamento de Ginecología y Obstetricia de la Facultad de Medicina, de la Universidad Nacional.

*** Jefe del Laboratorio del Distrito Materno Infantil.

(*) Naxocin Carlo Erba. 
De estos compuestos investigados hasta la fecha, solamente el metronidazol ha sido utilizado clínicamente como tricomoniacida sistémico, pero muchos de sus compuestos son a menudo inactivos por administración oral, probablemente porque no son bien absorbidos.

La Nitromidazina: ( 1-N (E-ethil Morpholine)-5-Nitroimidazole, es un nuevo derivado imidazólico estudiado por de Carneri que posee efectos altamente tricomoniacidas por vía oral y por vía tópica, demostrados ampliamente in vitro e in vivo (1). Su toxicidad es muy baja y por métodos microbiológicos se ha comprobado que los niveles sanguíneos y urinarios efectivos se consiguen después de la administración oral de $250 \mathrm{mg}$. del fármaco, a diferencia del metronidazol que requiere dosis de 750 mg. (2).

El producto en forma de óvulos para aplicación tópica, es la realización de una moderna asociación farmacéutica de efectos tricomonicidas, antibacterianos y antimicóticos, ya que es de regla la asociación de las tricomonas con gérmenes inespecíficos, como se demuestra en nuestro estudio y con monilias, según demuestran otros autores (3).

\section{Presentación del producto}

El producto se presenta en dos formas diversas:

\section{1) $\mathrm{NAXOCIN} \mathrm{comprimidos}$}

Nitroimidazina (1-(N-B-etilmorfolin)5-Nitroimidasol

Excipientes hasta

$250 \mathrm{mg}$. $400 \mathrm{mg}$.

2) NAXOCIN óvulos vaginales

Tipo A

Nitroimidazina

Nistatina

Quemicetina

Excipientes hasta
$250 \mathrm{mg}$.

$50.000 \mathrm{U}$.

$250 \mathrm{mg}$.

$1 \mathrm{gm}$.
Tipo B

Nitroimidazina

Nistatina

Excipientes hasta

$250 \mathrm{mg}$ $50.000 \mathrm{U}$.

$1 \mathrm{gm}$.

Las investigaciones microbiológicas han demostrado que la nitroimidazina ya a la concentración de 0,3 ug/1, posee una alta acción tricomonicida in vitro e in vivo y que además es activa también sobre la Entamoeba histolytica y sobre la Giardia lamblia.

Numerosos tests, hechos sobre animales de laboratorio y sobre órganos aislados in vitro, han permitido confirmar que la nitroimidazina no posee actividad farmacológica tal de traducirse en efectos colaterales a niveles del sistema nervioso central y del sistema nervioso vegetativo.

Las pruebas toxicológicas (particularmente importantes tratándose de un fármaco que obra por vía sistémica) han puesto en evidencia que la niotroimidazina, gracias a su escasa toxicidad, posee un elevadísimo coeficiente terapéutico, que confiere al producto una óptima tolerabilidad.

La toxicidad aguda, valorada por medio de la DL50, ha resultado en el ratón, de $3.250 \mathrm{mg} . / \mathrm{kg}$.

A dosis de $250 \mathrm{mg} / \mathrm{kg}$. diaria la nitroimidazina en el ratón no produce efectos imputables e intoxicaciones crónicas, ni tiene alteraciones de los parámetros hematológicos y hematoquímicos.

Experimentos hechos sobre animales del laboratorio, permiten, en fin, concluir que el Naxocin a dosis terapéuticas, no provoca de ningún modo alteraciones en la fecundación, en el anidamiento del huevo y en el órganogénesis fetal, por lo cual se pueden excluir daños de tipo teratogenético (1).

\author{
Rev. Col. Obst. y Ginec.
}




\section{Materiales y Métodos}

Se investigaron y trataron en el Departamento de Ginecología y Obstetricia de la Facultad de Medicina de la Universidad Nacional, 52 pacientes del sexo femenino, a las cuales se les suministró el tratamiento que se detalla posteriormente.

Cuarenta cónyuges fueron tratados, teniendo en cuenta la premisa básica de que es indispensable el tratamiento del hombre, para evitar el peligro de reinfección. Quince de estos cónyuges, fueron estudiados clínicamente y bacteriológicamente; los 25 restantes no fueron investigados por dificultad para concurrir al servicio. Las pacientes escogidas para la investigación, presentaban tricomoniasis genital comprobada clínicamente, con exámenes directos en fresco y con Citología.

A las parejas en investigación, se les suministró la droga en la siguiente forma: tratamiento por vía oral, 2 comprimidos diarios de "Naxocin" durante 6 días. Simultáneamente a la mujer 1 óvulo diario de "Naxocin" Tipo A ० B, vía vaginal por 6 días.

Terminado el tratamiento, la paciente se controlaba clínica y bacteriológicamente y estos controles se repetían después de 30 y 60 días, practicando cultivos si no se encontraba la tricomoniasis.

Los varones investigados lo fueron, por examen directo de la secreción uretroprostática y por cultivo.

Se determinaron los efectos colaterales producidos por la droga, tanto sistémicos, como locales.

\section{Procesamiento de las muestras de secreciones vaginales $y$ de líquidos prostáticos}

1. Secreciones vaginales: las muestras obtenidas se enviaron al Labo- ratorio, suspendidas en solución isotónica $\mathrm{NaCl}$. Estas muestras fueron mantenidas en la incubadora por un término medio de 30 minutos, para devolver así, la movilidad de las tricomonas facilitando su hallazgo en las secreciones examinadas. Transcurrido este tiempo, se practicó un examen en fresco de la muestra. Aquellas muestras que fueron negativas para formas de tricomonas vaginales, en fresco, se cultivaron en el medio de Diamond, cuya composición es la siguiente:

$\begin{array}{lr}\text { Tripticase } & 20 \mathrm{grm} . \\ \text { Yeast extrac } & 10 \mathrm{grm} . \\ \text { Maltosa } & 5 \mathrm{grm} . \\ \text { Cysteino HCl } & 1 \mathrm{grm} . \\ \text { Acido Ascórbico } & 0,5 \mathrm{grm} . \\ \text { Agar en polvo } & 0,5 \mathrm{grm} .\end{array}$

Se disuelven los componentes en $900 \mathrm{cc}$. de agua destilada y se ajusta al $\mathrm{pH}$ a 6,0, hervir para terminar la disolución y envasar en tubos para cultivo, con tapa de rosca, en cantidades de 4,5 cc. en cada uno.

Se mantienen en la nevera y dura apto para su uso, de 2 a 3 semanas. Inmediatamente antes de usarlo, se le agrega a cada tubo, 0,5 cc. de suero humano, al que ha sido ajustado el $\mathrm{pH}$ a 6,0 y 0,5 cc. de una mezcla de Penicilina - Streptomycina conteniendo 500 Unidades de cada antibiótico por cc.

Todos los lotes preparados, del medio de Diamond, fueron ensayados antes del uso, practicando en dos de ellos la siembra de muestras que al examen en fresco fueron positivos, para Trichomonas vaginalis. Se examinaron a las 48,72 y 96 horas, habiendo dado resultados positivos, es decir, se hallaron formas de Trichomonas vaginalis, vivas y móviles.

Se practicó, además, una coloración Gram, sobre las muestras enviadas para investigar la presencia del B. de 
Marzo-Abril 1970

Rev. Col. Obst. y Ginec.

Doderlein y la flora de asociación en cada caso.

En las muestras de secreción vaginal, no se practicó la determinación del $\mathrm{pH}$, debido a que fueron enviadas suspendidas en solución isotónica de $\mathrm{NaCL}$ y en esta forma el $\mathrm{pH}$, no sería el de la muestra. Sinembargo, y en forma cualitativa, se puede apreciar la acidez o alcalinidad de la muestra, por la presencia en mayor - menor grado del B. de Dóderlein, cuyo papel es el de mantener el medio vaginal ácido. La disminución y ausencia, casi absoluta de él, indica una alcalinización más o menos marcada del pH de la secreción examinada.

2. Las muestras de líquido prostático, recibieron el mismo tratamiento de las secreciones vaginales, es decir, un examen en fresco, coloración de Gram y cultivos en el medio de Diamond.

\section{Resultados}

Pacientes investigadas

Hombres investigados

\section{Grupos de edades de las pacientes investigadas}

$\begin{array}{llll}20 & \text { a } & 29 & \text { años } \\ 30 & \text { a } & 39 & \text { años } \\ 40 & \text { a } & 49 & \text { años }\end{array}$

TOTAL

\section{Diagnóstico}

A todas las pacientes se les practicó examen citológico, estudio microscópico en fresco y por coloración; los resultados fueron los siguientes:

Diagnósticos por Citología Vaginal

Diagnósticos por Citología y examen directo en fresco

Diagnósticos por examen directo en fresco

A los 15 cónyuges investigados, se les practicó examen de la secreción uretroprostática, haciendo la investigación microscópica en fresco, por coloración y por cultivo, encontrando solo un caso de tricomoniasis diagnosticada al efectuar el examen directo. Todos los cultivos practicados en hombres fueron negativos.

\section{Frotis vaginal. Resultados}

En 41 pacientes se encontraron tricomonas en el examen directo en fresco y la apreciación de la cantidad del protozoario se hizo en la siguiente forma:

Tricomonas escasas en
Tricomonas abundantes en
Tricomonas muy abundantes en 8 pacientes*
pacientes $* * * *$

No se encontró en ningún caso flujo tricomoniásico puro; las asociaciones más frecuentes fueron con Bacilos Gram negativos Tipo E. Coli, flora cocobacilar Gram negativa, estafilococo y estreptococo. No se encontró en ningún caos asociación con Cándida Albicans.

En los 11 casos restantes, el diagnóstico de tricomoniasis se hizo por Citología Vaginal; la coloración de Papanicolaou las revela en su forma piriforme característica, su coloración azul verdosa y la presencia en ocasiones de flagelos. Este método coadyuvante en el diagnóstico de tricomoniasis vaginal es considerado por nosotros de gran valor.

\section{Exámenes clínicos}

Las pacientes fueron sometidas a un completo examen clínico ginecológico al practicar las tomas iniciales de las muestras y en los controles posteriores. La totalidad de las enfermas presentaron antes de iniciar el tratamiento, flujo que fue catalogado como muy abundante en 14 casos y abundante en 37 casos. Ocho de las pacientes examinadas presentaron inicialmente vaginitis muy severas, con prurito e inflamación intensos. Nueve casos presentaron cervicitis que fueron tratadas adecuadamente. 


\section{Tratamiento}

A las 52 pacientes en estudio se les instituyó tratamiento oral a base de Nitroimidazina, bajo la forma farmacéutica de comprimidos de 250 mg., a razón de 2 diarios durante 6 días y aplicación simultánea de óvulos del Tipo A en 24 pacientes y del Tipo B en 28 pacientes.

A los cónyuges de las 40 pacientes que llevaban vida marital, se les suministraron 2 comprimidos diarios de Nitroimidazina de 250 mg. durante 6 días.

\section{Intolerancia a la droga}

Los fenómenos de intolerancia a la droga fueron mínimos; una sola paciente presentó diarrea y urticaria que cedió con adminsitración de antihistamínicos. Con el tratamiento tópico 10 pacientes relataron sensación de ligero ardor vaginal de muy corta duración.

La disgregación de los óvulos fue completa en 50 casos; 2 pacientes relataron disgregación casi total.

\section{Controles}

Instituído el tratamiento, las pacientes se citaron para un primer control clínico y bacteriológico al día siguiente de la terminación del tratamiento; todas las pacientes concurrieron a este primer control.

Un segundo control se efectuaba 30 días más tarde, a él concurrieron 39 pacientes.

\section{Resultados terapéuticos}

De las 52 pacientes investigadas el $100 \%$ acusó mejoría clínica notable en el primer control, con desaparición del prurito, disminución apreciable de la cantidad del flujo. El control bacteriológico por examen en fresco, coloración y cultivo, fue negativo por tricomonas en todas las pacientes.

De las 39 pacientes que concurrieron al segundo control efectuado 30 días más tarde, continuaban curadas clínica y bacteriológicamente 37 . Dos presentaron recurrencia bacteriológica (escasos tricomonas presentes en el frotis directo).

A estas dos pacientes se les prescribió un segundo tratamiento con curación completa clínica y bacteriológica en controles efectuados a los 90 y 120 días.

Las 27 pacientes que concurrieron al tercer control se encontraban curadas clínica y bacteriológicamente.

\section{Resumen y Conclusiones}

1\% Se estudiaron 52 mujeres con diagnóstico clínico, citológico y bacteriológico de tricomoniasis y se trataron con Nitroimidazina por vía oral y tópica.

2. Se estudiaron 15 cónyuges con examen bacteriológico y cultivo de la secreción uretroprostática, encontrándose solo un caso de tricomoniasis al examen directo en fresco.

3. Se efectuó el tratamiento de todas las parejas, aunque los hombres no fueron investigados en su totalidad, ya que se considera que la tricomoniasis es una entidad conyugal.

4: Todas las pacientes concurrieron al primer control, comprobándose en ellas mejoría clínica y ausencia de tricomonas en el examen directo $y$ en el cultivo. Treinta y nueve pacientes concurrieron a un segundo control. En treinta y siete no se evidenciaron tricomonas al examen directo $y$ en los cultivos. Dos presentaron recurrencia bacteriológica; se les prescribió un segundo tratamiento y en controles de 90 y 120 días, no se evidenciaron tricomonas. 
Veintisiete pacientes concurrieron a un tercer control no evidenciándose tricomonas en el examen directo ni en los cultivos.

5. Veinticuatro pacientes fueron tratadas con óvulos de Tipo A (conteniendo Quemicetina) y 28 con óvulos de Tipo B ( $\sin$ Quemicetina). En ambos grupos los resultados terapéuticos fueron similares; por esta razón solo aconsejamos la administración de óvulos del Tipo A en aquellas pacientes en las cuales predomine la asociación de gérmenes inespecíficos sobre las tricomonas.

6: Concluímos por nuestra investigación la óptima acción tricomonicida de la Nitroimidazina; la ausencia casi total de efectos secundarios y la excelente respuesta al tratamiento por vía oral y vaginal.

\section{BIBLIOGRAFIA}

1 DE CARNERI e coll.: Nitrimidazina: a new systemic Trichomoniacide. 6th Internat. Congress of Chemotherapy. Tokyo. August 10th to 15 th, 1969.

2 EMANUELI A., DE CARNERI I.: Clinical trials with nitrimidazine, a new sistemic trichomoniacide. 6th Internat. Congress of Chemotherapy. Tokio. August 10th to 15th, 1969.

3 HARTGILL, J. C. Diagnosis and treatment of vaginitis. Practitiones. 202; 363, 1969.

4 NOVAK, E. JONES, G. y JONES H. Tratado de Ginecología. Séptima Edición. Pág. 190. Editorial Interamericana, S. A. México, 1966.

5 ROGNONI V.: Trattamento locale delle vaginiti con particolare riguardo a quelle da trichomonas vaginalis. Riv. Obstet. e Ginec. Practica (in corso di stampa).

6 ROGONI V., SIDERI I.: Trattamento delle vaginiti con particolari riguardo alle forma di patogenesi protozoaria. Riv. Obstet. e Ginec. 